\title{
Cervical spine curvature during simulated whiplash
}

\author{
Manohar M. Panjabi ${ }^{\text {a,* }}$, Adam M. Pearson a, Shigeki Ito a , Paul C. Ivancic ${ }^{\text {a }}$, \\ Jaw-Lin Wang ${ }^{b}$ \\ a Biomechanics Research Laboratory, Department of Orthopaedics and Rehabilitation, Yale University School of Medicine, 333 Cedar St., \\ P.O. Box 208071, New Haven, CT 06520-8071, USA \\ ${ }^{\mathrm{b}}$ Institute of Biomedical Engineering, National Taiwan University, Taipai, Taiwan
}

Received 11 April 2003; accepted 18 September 2003

\begin{abstract}
Objective. To develop a new method to describe cervical spine curvature and evaluate the potential for injury in the upper and lower cervical spine during simulated whiplash.

Design. A method was developed to integrate the upper and lower cervical spine rotations and describe the spine curvature.

Background. In vivo and in vitro whiplash simulations have documented the development of an S-shape curvature with simultaneous upper cervical spine flexion and lower cervical spine extension immediately following rear-impact. Investigators have hypothesized that the injury potential is highest during the S-shape phase. However, little data exist on the spine curvature during whiplash and its relation to spine injury.

Methods. A biofidelic model and a bench-top whiplash apparatus were used in an incremental rear-impact protocol (maximum $8 \mathrm{~g})$ to simulate whiplash of increasing severity. To describe the spine curvature, the upper and lower cervical spine rotations were normalized to corresponding physiological limits.

Results. Average peak lower cervical spine extension first exceeded the physiological limits $(P<0.05)$ at a horizontal T1 acceleration of $5 \mathrm{~g}$. Average peak upper cervical spine extension exceeded the physiological limit at $8 \mathrm{~g}$, while peak upper cervical spine flexion never exceeded the physiological limit. In the S-shape phase, lower cervical spine extension reached $84 \%$ of peak extension during whiplash.

Conclusions. Both the upper and lower cervical spine are at risk for extension injury during rear-impact. Flexion injury is unlikely.
\end{abstract}

\section{Relevance}

The present study helps to identify the location and mechanism of whiplash injury and should be of benefit to clinicians and engineers.

(c) 2003 Elsevier Ltd. All rights reserved.

Keywords: Whiplash; Rear impact; Cervical spine; Curvature; Kinematics

\section{Introduction}

Whiplash-associated disorders have a prevalence of $1 \%$ in the United States and cost an estimated 10 billion euros per year in Western Europe (Barnsley et al., 1994; Richter et al., 2000). Clinical investigations have suggested that whiplash can cause injury to the facet joints in both the upper cervical spine (UCS) and lower cervical spine (LCS) (Barnsley et al., 1995; Bogduk and

\footnotetext{
${ }^{*}$ Corresponding author.

E-mail address: manohar.panjabi@yale.edu (M.M. Panjabi).
}

Marsland, 1988; Lord et al., 1996) and to the intervertebral discs in the LCS (Jonsson et al., 1994; Pettersson et al., 1997). While the mechanisms of injury were largely unknown in the past (Barnsley et al., 1994; Spitzer et al., 1995), recent studies have implicated an S-shape curvature of the cervical spine.

In vivo and in vitro biomechanical studies have demonstrated that the cervical spine develops an Sshape curvature-simultaneous UCS flexion and LCS extension, immediately following rear-impact. In an in vivo study, initial UCS flexion was documented in the majority of subjects, however, rotational data were not reported (Matsushita et al., 1994). In another in vivo 
study, the one volunteer was found to have maximum UCS flexion of $5^{\circ}$ at C3-C4 (Kaneoka et al., 1997). Multiple in vitro studies using whole cadavers (Geigl et al., 1994; Luan et al., 2000), whole cervical spine models (Grauer et al., 1997) and head-neck constructs (Cusick et al., 2001; Yoganandan et al., 1996) have also demonstrated the development of an S-shape cervical spine curvature during the initial phase of whiplash. It has been hypothesized that the potential for injury during the S-shape phase is high since injurious intervertebral rotations may occur prior to the contact of the head with the headrest, and before the cervical musculature can exert their protective effect, if any (Grauer et al., 1997; Panjabi et al., 1998a).

Based upon the UCS and LCS kinematics during simulated whiplash, investigators have hypothesized that UCS components are at risk of flexion injury, while LCS components are at risk due to hyperextension. Cusick et al. (2001) and Yoganandan et al. (1998) concluded that neural structures in the UCS and the facet joints in the LCS are at risk of injury during the S-shape phase. It has also been suggested that the UCS capsular ligaments are at risk of injury due to facet joint separation during UCS flexion (Luan et al., 2000). Other investigators have hypothesized that changes in the cerebrospinal fluid pressure during the S-shape phase of whiplash may cause spinal ganglia injury (Eichberger et al., 2000; Svensson et al., 2000). The majority of the whiplash injury mechanism hypotheses focus on potential injury during the S-shape phase of whiplash.

The S-shape curvature of the cervical spine has been well documented in qualitative terms, however it has not been subjected to detailed quantitative analyses. The absolute and relative magnitudes of UCS and LCS rotations, and their temporal behavior have not been determined. Accordingly, the goals of the present study were to develop a new method to evaluate the cervical spine curvature during simulated whiplash and to identify the temporal and spatial loci at which the potential for cervical spine whiplash injury exists.

\section{Methods}

\subsection{Specimen preparation}

Five fresh-frozen human whole cervical spine (WCS) specimens consisting of the occiput $(\mathrm{C} 0)$ to $\mathrm{T} 1$ vertebra (average age 71 years, range 52-84 years) were prepared by carefully removing all non-osteoligamentous soft tissues. Apart from typical age-related changes, the donors had not suffered head or neck trauma and did not suffer from any disease that could have affected the osteoligamentous structures. To prepare a specimen, the occiput and $\mathrm{T} 1$ were set in two parallel horizontal resin mounts (Fibre Glass-Evercoat, Cincinnati, OH, USA).
The specimen was oriented in the neutral posture during the mounting procedure, such that a line from the top of the dens to the lowest point on the posterior occiput was parallel to the occipital mount and the T1 vertebra was tilted anteriorly by $24^{\circ}$ (Braakman and Penning, 1971). For attachment of motion measuring flags, sagitally aligned headless wood screws were drilled into the anterior aspect of each vertebral body (C2 through C7) and through the left lateral mass of $\mathrm{C} 1$. This constituted the WCS model.

\subsection{Physiological motions}

To prepare the WCS model for the intact flexibility testing to determine physiological spinal motions, a loading jig was attached to the occipital mount, while the T1 mount was fixed. The weights of the loading jig and occipital mount were counterbalanced. Pure flexion and extension moments were applied to the occipital mount in four equal steps up to peak loads of $1.5 \mathrm{~N} \mathrm{~m}$ (Panjabi et al., 1998c). To allow for viscoelastic creep, 30 $\mathrm{s}$ wait periods were given following each load application. After two preconditioning cycles, digital images were recorded using a digital camera.

\subsection{Incremental whiplash simulation}

For whiplash simulation, the WCS model was stabilized with the compressive muscle force replication (MFR) system (Panjabi et al., 2001) and adjusted to enhance the dynamic response during whiplash simulation (Fig. 1). Stainless steel lateral guide rods $(3.0 \mathrm{~mm}$ diameter) were inserted into the vertebral bodies in the frontal plane through the approximate centers of rotation of each intervertebral joint. Since $\mathrm{C} 1$ does not have a vertebral body, no rod was inserted at this level. A surrogate head with a mass of $3.3 \mathrm{~kg}$ and sagittal plane moment of inertia of $0.016 \mathrm{~kg} \mathrm{~m}^{2}$ was attached to the occipital mount (Becker, 1972; Walker et al., 1973). The MFR system consisted of anterior, posterior and eight lateral cables attached to springs anchored to the base, each pre-loaded to $30 \mathrm{~N}$. Anterior and posterior cables originated at the occipital mount, ran along the anterior and posterior aspects of the specimen, and were connected to the springs. Bilateral MFR cables originated from $\mathrm{C} 0, \mathrm{C} 2, \mathrm{C} 4$, and $\mathrm{C} 6$, passed along the lateral guide rods, ran through pulleys at the $\mathrm{T} 1$ mount, and were attached to the springs. The stiffness coefficient of each spring was $4.0 \mathrm{~N} / \mathrm{mm}$. With this MFR arrangement, the compressive pre-loads at various intervertebral levels were: $120 \mathrm{~N}(\mathrm{C} 0-\mathrm{C} 1, \mathrm{C} 1-\mathrm{C} 2) ; 180 \mathrm{~N}(\mathrm{C} 2-\mathrm{C} 3, \mathrm{C} 3-\mathrm{C} 4)$; $240 \mathrm{~N}$ (C4-C5, C5-C6); and $300 \mathrm{~N}$ (C6-C7, C7-T1). A $\mathrm{C} 0-\mathrm{C} 2$ flexion modulator was used to simulate the effect of contact between the chin and the anterior cervical structures (i.e. skin, subcutaneous fat, strap muscles, sternum) on flexion of $\mathrm{C} 0-\mathrm{C} 1$ and $\mathrm{C} 1-\mathrm{C} 2$ (Panjabi et al., 
WCS+MFR Model

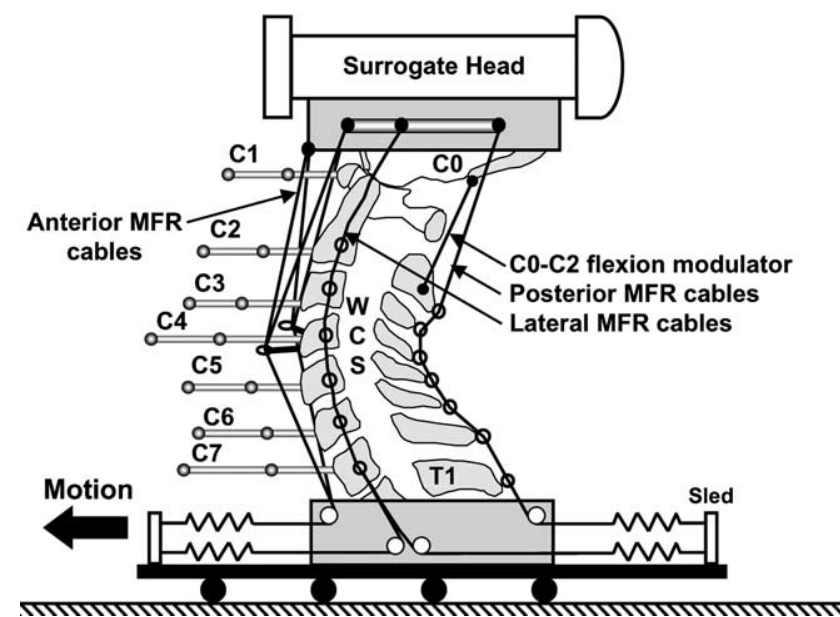

Fig. 1. Whole cervical spine (WCS) specimen mounted on the whiplash sled and prepared for rear-impact with the muscle force replication (MFR) system, $\mathrm{C} 0-\mathrm{C} 2$ flexion modulator, movie flags and surrogate head.

2001). During whiplash simulation, the surrogate head and WCS were stabilized with compressive MFR without requiring a tensile force to counterbalance the head or a head stop to restrict the head extension. This constituted the WCS + MFR model.

Using a previously described bench-top apparatus (Ivancic et al., 2002; Panjabi et al., 1998a), the WCS + MFR model was subjected to whiplash simulation using the incremental trauma approach at four nominal maximum $\mathrm{T} 1$ horizontal accelerations: 3.5, 5, 6.5 , and $8 \mathrm{~g}$. The major components of the whiplash apparatus included the sled, impacting mass, and the braking system (Panjabi et al., 1998a). Two high-speed cameras (Kodak Motion Corder, Fast Cam, Super 10k and model PS-110, Eastman Kodak Company, Rochester, NY, USA) arranged sequentially recorded the motion of the head and vertebral flag markers at 500 frames/sec. Custom Matlab programs were written to obtain sub-pixel accuracy to track the motions of the flag markers and to calculate the UCS and LCS rotation throughout whiplash (Matlab, The Mathworks Inc., Natick, MA, USA).

\subsection{Error analysis}

A custom jig was designed to determine the overall error in the calculation of the UCS and LCS rotations during simulated whiplash, which included errors associated with the measurement system, the motion tracking software, and the computation of intervertebral angles. The jig consisted of two motion tracking flags, each with two markers. The top flag was rotated in extension relative to the fixed lower flag using a precision rotator (resolution $0.001^{\circ}$, Oriel Corporation, Stamford,
CT) in 50 increments of $0.2^{\circ}$ each, and an image was recorded by the high-speed camera at each step. The motion tracking software was used to track the positions of the markers and to calculate the angle change between the flags. The average (SD) rotation error in the $10^{\circ}$ range was $0.05^{\circ}\left(0.27^{\circ}\right)$.

\subsection{Cervical spine curvature}

A new methodology was developed to evaluate the cervical spine curvature during whiplash simulation. In previous whiplash simulations, two distinct cervical spine curvatures were observed. Immediately following impact, the cervical spine developed an S-shape curvature-simultaneous UCS flexion and LCS extensionand then formed a C-shape curvature-extension of the entire cervical spine (Grauer et al., 1997; Kaneoka et al., 1999; Panjabi et al., 1998b). During the S-shape phase, a vertebral inflection point (IP) may be defined such that the intervertebral levels above the IP were in flexion and those below were in extension. The IP was determined for each specimen during whiplash. The intervertebral rotations for the spinal levels above and below the IP were separately summed and normalized to the corresponding physiological rotations obtained during flexibility testing. Thus, the normalized upper cervical rotation $\left(\theta_{\text {Upper }}\right)$ and lower cervical rotation $\left(\theta_{\text {Lower }}\right)$ were given by the following:

$$
\begin{aligned}
& \theta_{\text {Upper }}(t)=\frac{\sum_{i=\mathrm{C} 0-\mathrm{C} 1}^{m} \theta_{\text {Whiplash }, i}(t)}{\sum_{i=\mathrm{C} 0-\mathrm{C} 1}^{m} \theta_{\mathrm{Phys}, i}}, \\
& \theta_{\text {Lower }}(t)=\frac{\sum_{i=n}^{\mathrm{C} 7-\mathrm{T} 1} \theta_{\text {Whiplash }, i}(t)}{\sum_{i=n}^{\mathrm{C} 7-\mathrm{T} 1} \theta_{\mathrm{Phys}, i}},
\end{aligned}
$$

where

- $i$ represented the intervertebral level $(\mathrm{C} 0-\mathrm{C} 1$ to $\mathrm{C} 7-$ $\mathrm{T} 1)$,

- $m$ and $n$ represented the intervertebral levels superior and inferior to the IP, respectively,

- $\theta_{\text {Whiplash, } i}$ represented the rotation (flexion or extension) of intervertebral level $i$ during whiplash,

- $\theta_{\mathrm{Phys}, i}$ represented the physiological range of motion in either flexion or extension (corresponding to $\left.\theta_{\text {Whiplash }, i}\right)$ at intervertebral level $i$.

To separate the total physiological range of motion into flexion and extension components, a neutral position was defined for each intervertebral level such that the neutral position divided the neutral zone into equal flexion and extension components during the intact flexibility testing (Panjabi, 1992). To determine the curvature of the cervical spine throughout the head extension phase of whiplash, a phase diagram was created by plotting the normalized rotation of the UCS vs. the normalized rotation of the LCS. 


\subsection{Data analyses}

The normalized UCS and LCS rotation data were low pass digitally filtered at a cut-off frequency of $30 \mathrm{~Hz}$. The peak normalized UCS and LCS rotations during the head extension phase (i.e. from the onset of T1 acceleration to return to the neutral posture, after maximum head extension) and the times at which the peaks occurred were determined for each whiplash simulation. The magnitude and time of the maximum LCS extension during the S-shape phase were also determined.

Single factor, repeated measures ANOVA and Bonferonni post-hoc tests were used to determine significant increases $(P<0.05)$ in the average normalized rotation peaks during whiplash as compared to the corresponding average physiological rotations. To determine the temporal event patterns, pair-wise comparisons were made between the average times of the rotation peaks.

\section{Results}

\subsection{The phase plot and a representative example}

Specimen \#2 (8 g simulation) was chosen to illustrate the curvature of the cervical spine during simulated whiplash. The results are first presented in the traditional rotation vs. time plot (Fig. 2A). The simulation is divided into $\mathrm{S}$ - and $\mathrm{C}$-shape phases. The physiological rotation band (shaded gray, \pm 1.0 normalized rotation) indicates the safe curvature region for both the UCS and LCS. Also indicated are the time course (50 ms increments) and the peak head extension. The LCS curve left the physiological band at $74 \mathrm{~ms}$, while the UCS curve left at $128 \mathrm{~ms}$, indicating that the LCS is at risk early in whiplash trauma.

The second representation of the results is the UCS vs. LCS rotation phase plot (Fig. 2B). The plot is divided into four quadrants: S-shape, C-shape (flexion), inverse $\mathrm{S}$-shape, and $\mathrm{C}$-shape (extension). Also notice the physiological bands for the UCS (horizontal band, \pm 1.0 UCS normalized rotation), LCS (vertical band, \pm 1.0 LCS normalized rotation), and the physiological square at the intersection of the two bands representing the safe curvature region for both the UCS and LCS. The areas outside the physiological square represent the potential injury zones, with the white regions representing potentially injurious curvature of both the UCS and LCS and the light gray regions representing potentially injurious curvature of only one cervical region. Following the onset of $\mathrm{T} 1$ horizontal acceleration $(t=0)$, the cervical spine developed an S-shape curvature (curve entered the S-shape quadrant), with UCS flexion and LCS extension. At $74 \mathrm{~ms}$, the curve left the LCS physiological band, but remained within the UCS physiological band. After reaching the UCS flexion peak of about 0.5 at $88 \mathrm{~ms}$, the curve dipped down, entering the C-shape quadrant. The transition from $\mathrm{S}$ - to C-shape curvature occurred as the UCS returned to the neutral posture at $108 \mathrm{~ms}$, at which point the LCS extension was greater than twice the physiological extension. The UCS continued to extend, reaching a peak extension of nearly twice the physiological at $150 \mathrm{~ms}$, while the peak LCS extension of 2.7 times the physiological occurred at $162 \mathrm{~ms}$, approximately coinciding with the peak head extension. Following the peak head extension, the cervical spine returned towards the neutral posture as both UCS and LCS extensions decreased to within the corresponding physiological ranges.

\subsection{Six specimens}

The inflection point (IP) was defined as the cervical vertebra at which the intervertebral levels above the IP were in flexion and the levels below the IP were in extension during the S-shape phase of whiplash. The IP ranged between $\mathrm{C} 2$ and $\mathrm{C} 4$ and varied among the specimens, but not among the impact accelerations (C2: specimen \#1, C3: specimens \#2 and \#3, C4: specimens \#4 and \#5).

During the $3.5 \mathrm{~g}$ impact, the phase plots for all specimens left the physiological LCS band but remained within the UCS physiological band (Fig. 3A). As the impact acceleration increased $(5,6.5$, and $8 \mathrm{~g})$, phase plots of increasing number of specimens left the UCS physiological band, in addition to leaving the LCS physiological band (Fig. 3B-D). At the final impact acceleration of $8 \mathrm{~g}$, the maximum LCS extension was 2.7 times the physiological, while the maximum UCS extension was 2.2 times the physiological (Fig. 3D). None of the specimens, at any impact acceleration, entered the flexion potential-injury zone.

The average peak normalized rotations of the UCS and LCS describe the potential injury sites and mode of injury (Table 1). The average peak LCS extension exceeded $(P<0.05)$ physiological LCS extension at $5 \mathrm{~g}$ and above, and the average peak UCS extension exceeded the physiological limit only at $8 \mathrm{~g}$. Average peak UCS flexion never exceeded the physiological limit.

No statistically significant differences in the average times of the peak UCS and LCS rotations were observed among impact accelerations, so data from all accelerations were combined for analysis. The average peak UCS flexion occurred at $81.2 \mathrm{~ms}$, followed by the maximum $\mathrm{S}$ shape LCS extension at $116.8 \mathrm{~ms}$, and lastly by the peak extensions of the LCS, head and UCS at 163.6, 172.3, and $173.5 \mathrm{~ms}$, respectively (Table 2). Pairwise comparisons demonstrated that the peak UCS flexion and maximum S-shape LCS extension occurred separately, while the times of the peak extensions could not be differentiated.

To better understand the kinematics of LCS extension - the most likely mechanism of injury - the progression of LCS extension throughout the S-shape and 

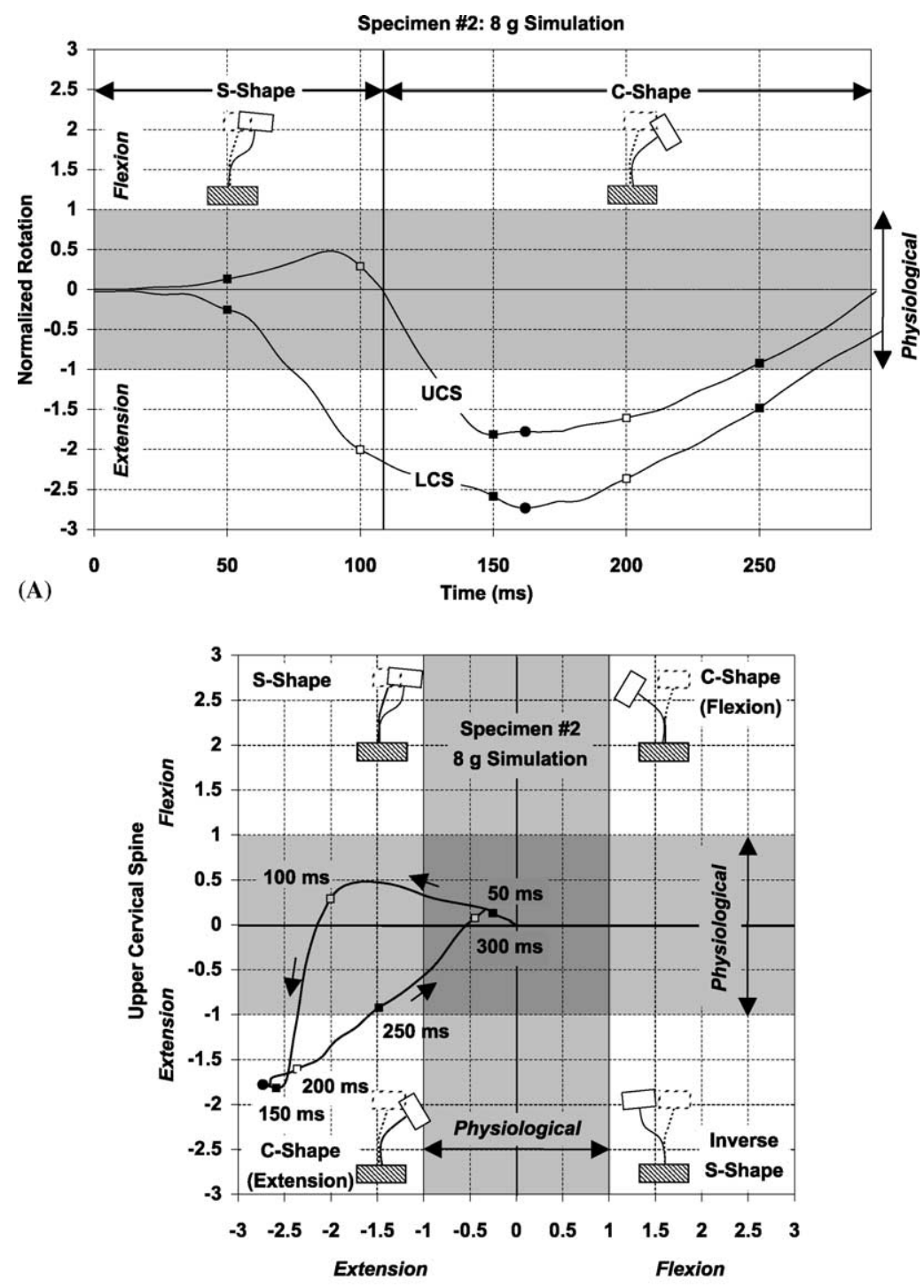

(B)

Lower Cervical Spine

Fig. 2. A representative example of cervical spine curvature during simulated whiplash (specimen \#2, $8 \mathrm{~g}$ whiplash simulation). The peak head

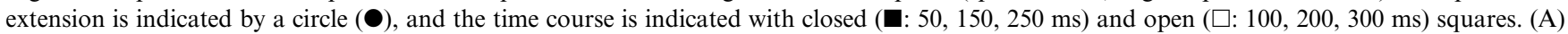
Traditional plot of the normalized rotation of the upper (UCS) and lower cervical spine (LCS) vs. time. The physiological rotation band is defined within the shaded rectangle. (B) The phase plot: normalized UCS rotation vs. normalized LCS rotation. The S-shape, C-shape (flexion), inverse Sshape and C-shape (extension) are each represented as a quadrant. The physiological rotation bands for the UCS (horizontal) and LCS (vertical) are indicated with lightly shaded rectangles, and their intersection (darkly shaded) forms the physiological square representing the safe curvature zone.

C-shape phases was analyzed. The maximum S-shape LCS extension was expressed as a percentage of the peak LCS extension at each impact acceleration. The average maximum LCS extensions during the S-shape phase were: $79.3 \%$ (SD 25.6\%), 87.0\% (SD 44.4\%), 82.9\% (SD $33.1 \%$ ), and $85.0 \%$ (SD $28.5 \%$ ) of the peak LCS extension at $3.5,5,6.5$, and $8 \mathrm{~g}$, respectively.

\section{Discussion}

A new methodology was utilized to determine the cervical spine curvature throughout simulated whiplash by normalizing the upper and lower cervical spine rotations to the physiological limits. By reducing the cervical spine to only two motion segments, this method allowed for a continuous analysis of the cervical spine curvature and injury potential. The present study has shown that as the UCS reached peak flexion at $81 \mathrm{~ms}$, the LCS continued to extend. Maximum LCS extension in the S-shape phase occurred at $117 \mathrm{~ms}$. During the S-shape phase, UCS flexion never exceeded the physiological limit, while LCS extension exceeded the physiological limit in the majority of specimens at $\mathrm{T} 1$ horizontal accelerations of $5 \mathrm{~g}$ and above. As the UCS transitioned from flexion to extension at the end of the 


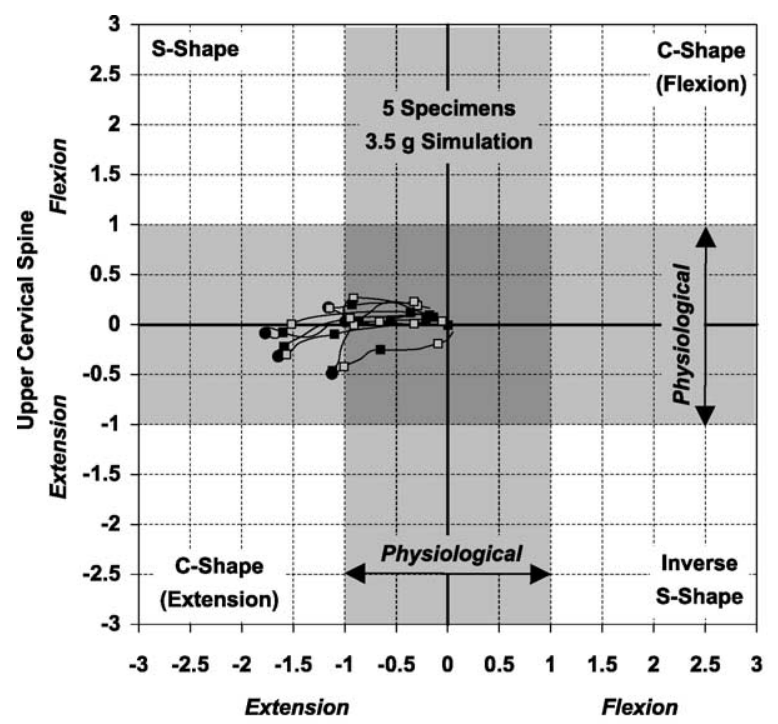

(A)

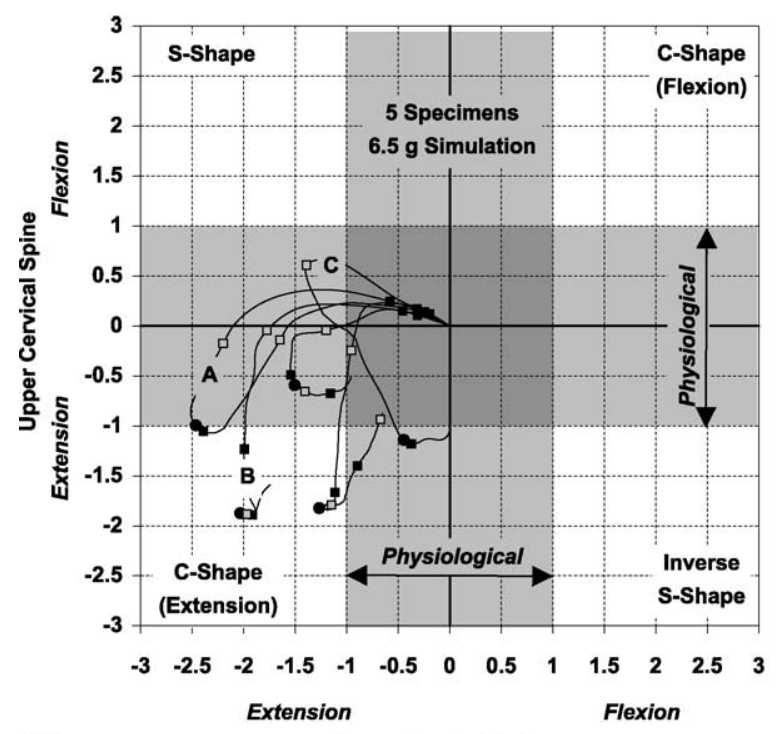

(C)
Lower Cervical Spine

Lower Cervical Spine

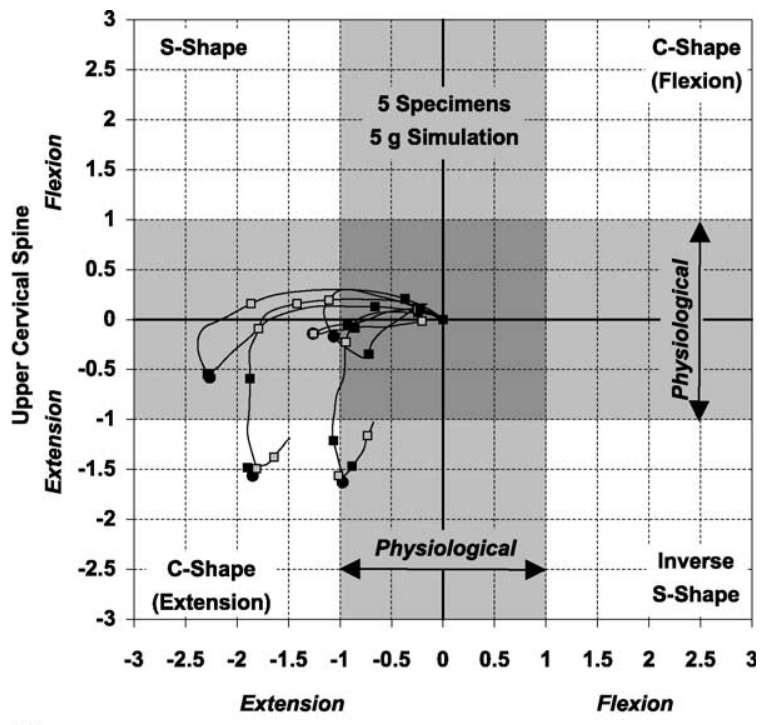

Lower Cervical Spine

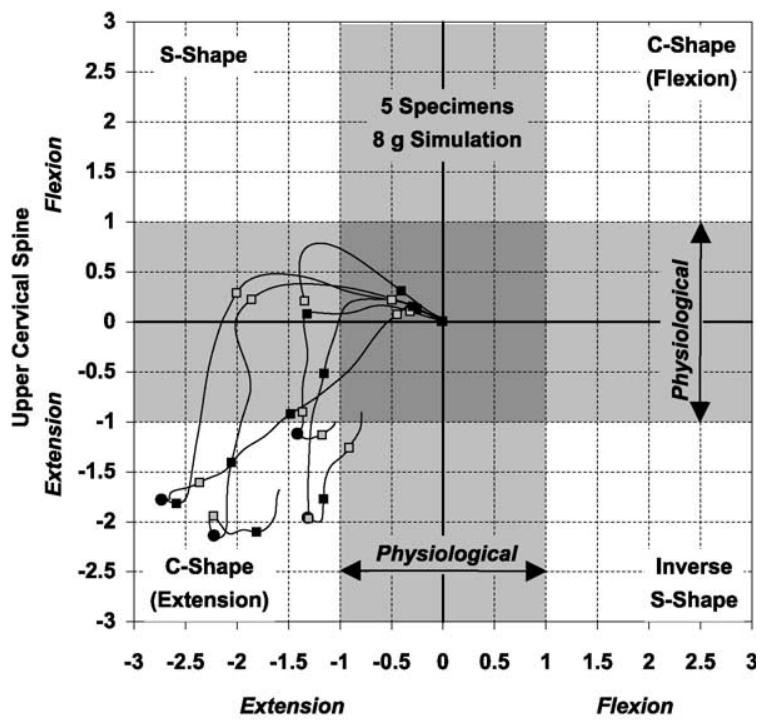

(D)

Lower Cervical Spine

Fig. 3. The phase plots of the five specimens during simulated whiplash at (A) $3.5 \mathrm{~g}$, (B) $5 \mathrm{~g}$, (C) $6.5 \mathrm{~g}$, and (D) 8 g. The normalized UCS rotation is plotted vs. the normalized LCS rotation. The S-shape, C-shape (flexion), inverse S-shape and C-shape (extension) are each represented as a quadrant. The physiological rotation bands for the UCS (horizontal) and LCS (vertical) are indicated with lightly shaded rectangles, and their intersection (darkly shaded) forms the physiological square representing the safe curvature zone. The peak head extension is indicated by a circle ( $)$, and the time course is indicated with closed ( $\mathbf{\square}: 50,150,250 \mathrm{~ms})$ and open ( $\square:$ 100, 200, $300 \mathrm{~ms})$ squares. The curves labeled A, B, and C in Fig. 3C are further described in Section 4.

S-shape phase, the LCS continued to extend and typically reached peak extension during the $\mathrm{C}$-shape phase. The peak UCS extension generally occurred simultaneously with the peak LCS extension and exceeded the physiological limits at higher impact accelerations.

Although the above description provides the typical cervical spine kinematics during whiplash simulation, certain variations were observed among specimens. To illustrate these interesting differences, the $6.5 \mathrm{~g}$ phaseplot curves (marked A, B, and C in Fig. 3C) of three specimens are described. All three curves left the LCS physiological band while still in the S-shape quadrant and proceeded along different paths into the $\mathrm{C}$-shape (extension) quadrant. After reaching peak UCS flexion, curve A continued down and to the left en route to peak UCS and LCS extensions. Thus, after peak UCS flexion, both UCS and LCS extensions increased until maximum head extension was reached. Curve B followed a similar course except that upon entering the C-shape (extension) quadrant, it proceeded straight downwards, indicating that UCS extension increased while the LCS posture did not change. The specimen represented by 
Table 1

Average (SD) normalized peak upper cervical spine (UCS) and lower cervical spine (LCS) flexion and extension during simulated whiplash at $\mathrm{T} 1$ horizontal accelerations of $3.5,5,6.5$, and $8 \mathrm{~g}$

\begin{tabular}{llll}
\hline $\begin{array}{l}\text { T1 horizontal } \\
\text { acceleration }(\mathrm{g})\end{array}$ & $\begin{array}{l}\text { Peak UCS } \\
\text { flexion }\end{array}$ & $\begin{array}{l}\text { Peak UCS } \\
\text { extension }\end{array}$ & $\begin{array}{l}\text { Peak LCS } \\
\text { extension }\end{array}$ \\
\hline 3.5 & $0.2(0.1)$ & $0.2(0.2)$ & $1.3(0.3)$ \\
5.0 & $0.2(0.1)$ & $0.9(0.7)$ & $1.6^{*}(0.6)$ \\
6.5 & $0.3(0.2)$ & $1.3(0.5)$ & $1.8^{*}(0.5)$ \\
8.0 & $0.4(0.2)$ & $1.8^{*}(0.4)$ & $1.8^{*}(0.6)$ \\
\hline
\end{tabular}

The UCS and LCS rotations were normalized to the corresponding physiological limits.

Significant increases $(P<0.05)$ over the physiological limits are indicated $\left({ }^{*}\right)$.

Table 2

Average (SD) times (ms) of events for the upper cervical spine (UCS) and lower cervical spine (LCS) during simulated whiplash

\begin{tabular}{lrl}
\hline Event & Time of event & $\begin{array}{l}\text { Significant } \\
\text { pairwise comparisons }\end{array}$ \\
\hline (1) Peak UCS flexion & $81.2(17.7)$ & $1-2,1-3,1-4,1-5$ \\
(2) Max S-shape LCS & $116.8(20.6)$ & $2-1,2-3,2-4,2-5$ \\
extension & & \\
(3) Peak LCS extension & $163.6(41.9)$ & $3-1,3-2$ \\
(4) Peak head extension & $172.3(34.3)$ & $4-1,4-2$ \\
(5) Peak UCS extension & $173.5(42.9)$ & $5-1,5-2$ \\
\hline
\end{tabular}

Significant $(P<0.05)$ pairwise comparisons are indicated for each event.

curve $\mathrm{C}$ demonstrated the most unusual kinematics. The specimen reached peak LCS extension shortly after peak UCS flexion, while still in the S-shape quadrant. The curve then proceeded down and to the right as the UCS transitioned from flexion to extension while LCS extension decreased. These differences in kinematics among the specimens are likely due to anatomic variation, such as differences in size and geometry, and suggest that multiple responses to whiplash loading are possible.

The limitations of the present study must be considered when formulating conclusions regarding the potential for injury during whiplash. This study compared the UCS and LCS rotations during simulated whiplash to the corresponding physiological rotations. The potential for injury existed when the dynamic whiplash rotation exceeded the corresponding physiological limit, i.e. the normalized UCS or LCS rotation was greater than 1.0. We defined the physiological rotation as that which resulted from the application of a $1.5 \mathrm{Nm}$ flexion or extension moment to the occipital mount of the specimen. The physiological rotations of the present study were within the in vivo physiological range (Dvorak et al., 1988; Ordway et al., 1999; Penning, 1978). Since the margin of safety beyond the physiological rotation at each of the spinal regions is unknown, the normalized UCS and LCS rotations only represent the injury potential, and do not necessarily correspond to real injury. Despite these limitations, we believe the present study provided valuable information concerning the dynamic spinal curvature and potential for cervical spine injury during whiplash. Although not addressed in the present study, an additional advantage associated with incremental whiplash simulation of the whole cervical spine model (Atlas et al., 2002; Panjabi et al., 2000a; Panjabi et al., 2000b) is the ability to quantify the soft tissue injury via differences in the pre- and postwhiplash flexibility parameters (Panjabi et al., 1998c).

There are few studies to which our results could be compared. Grauer et al. (1997) and coworkers used a WCS model without muscle force replication to simulate whiplash. They noticed the development of an S-shaped curvature early in the simulation, which transformed to a $\mathrm{C}$-shaped curvature as the trauma progressed. Intervertebral extension consistently exceeded the physiological at $\mathrm{C} 6-\mathrm{C} 7$ and $\mathrm{C} 7-\mathrm{T} 1$, while, in general, neither flexion nor extension exceeded physiological limits at upper cervical levels. They also noted that the peak extension of the lowermost intervertebral level occurred while $\mathrm{C} 0-\mathrm{C} 1$ and $\mathrm{C} 1-\mathrm{C} 2$ remained in flexion. The present study demonstrated that the peak LCS extension generally occurred during the C-shape phase of whiplash, although an average of $84 \%$ of peak LCS extension developed during the S-shape phase. Yoganandan et al. (1998) determined peak rotations for the upper (C0-C2), middle (C2-C5), and lower (C5-T1) cervical regions using a head-neck complex to simulate whiplash at $4.3 \mathrm{~g}$. The peak $\mathrm{C} 0-\mathrm{C} 2$ flexion was $5.2^{\circ}$ and well below the in vivo physiological $\mathrm{C} 0-\mathrm{C} 2$ flexion of $15^{\circ}-20^{\circ}$, while the peak $\mathrm{C} 0-\mathrm{C} 2$ extension was $32^{\circ}$, much in excess of the corresponding physiological extension of $15^{\circ}-20^{\circ}$ (Ordway et al., 1999; Penning, 1978). The peak C5-T1 extension marginally exceeded the physiological limits (White and Panjabi, 1990). Using a similar model, Cusick et al. (2001) reported a comparable peak $\mathrm{C} 0-\mathrm{C} 2$ flexion of approximately $5^{\circ}$. Studies using one or two whole cadavers have also demonstrated S-shape formation, though the results were variable (Geigl et al., 1994; Luan et al., 2000). In conclusion, the present study extends the findings of previous studies, demonstrating that UCS flexion remained within the physiological limits, while both UCS and LCS extension exceeded the physiological limits.

Several hypotheses have been put forward to predict which cervical spine components are at the greatest risk of injury during whiplash. It has been suggested that UCS flexion during the S-shape phase puts neural elements at risk of tensile injury (Cusick et al., 2001; Yoganandan et al., 1998) and the capsular ligaments at risk due to excessive facet joint separation (Luan et al., 2000). However, the composite evidence generated by the present study and prior studies suggest that UCS flexion during simulated whiplash was below physiological limits (Grauer et al., 1997; Ordway et al., 1999; 
Penning, 1978). The possibility that the S-shape curvature is non-physiological and puts the cervical spine at risk of injury due to intervertebral rotations within the physiological range is unlikely as in vivo studies of neck retraction ("chin-in" position) have documented the formation of an S-shape curvature with UCS flexion of equal magnitude to that seen during flexion of the entire cervical spine (Ordway et al., 1999; Penning, 1992). While clinical evidence suggests that $\mathrm{C} 2-\mathrm{C} 3$ facet joint injury can result from whiplash (Barnsley et al., 1995; Bogduk and Marsland, 1988; Lord et al., 1996), the kinematics observed during whiplash simulations do not suggest a corresponding flexion injury mechanism.

Others have hypothesized that LCS components such as the anterior longitudinal ligament, the intervertebral disc and the facet joint are at risk for injury due to hyperextension, and the results of the present and prior studies support these hypotheses (Kaneoka et al., 1999; Luan et al., 2000; Panjabi et al., 1998b). The present study has demonstrated that LCS extension exceeded physiological limits during both the S-shape and C-shape phases of simulated whiplash. The peak LCS extension occurred in the $\mathrm{C}$-shape phase at an average of $164 \mathrm{~ms}$ following the onset of T1 horizontal acceleration. In real-life accidents, the activation of cervical musculature as well as the contact of the head with the headrest may protect the spine. Though the peak LCS extension did occur in the C-shape phase, an average of $84 \%$ of the peak LCS extension developed during the S-shape phase, within $117 \mathrm{~ms}$ of the onset of T1 horizontal acceleration. Since peak muscle forces cannot be developed within 117 ms (Kumar et al., 2002; Magnusson et al., 1999; Ono et al., 1997; Svensson et al., 1993; Szabo and Welcher, 1996), and the head is unlikely to contact the headrest during the S-shape phase, the results of the present study suggest that the lower cervical spine may be more likely to suffer extension injuries during the $\mathrm{S}$-shape phase than during the $\mathrm{C}$-shape phase.

\section{Conclusions}

In summary, the results of the present study suggest that the cervical spine initially develops an S-shape curvature and then progresses to a C-shape curvature during whiplash. The LCS is at risk for extension injury during both the S-shape and C-shape phases of whiplash. However, the risk may be higher during the $\mathrm{S}$-shape phase as the cervical muscles and headrest are unlikely to prevent injury in this early phase of whiplash. While flexion injury of the UCS is unlikely, the potential for UCS extension injury exists at higher impact accelerations. We hope that this complete description of the S- and C-shape curves of the cervical spine throughout simulated whiplash may contribute to better prevention, diagnosis and treatment of whiplash injuries.

\section{Acknowledgements}

This research was supported by NIH Grant 1 R01 AR45452 1A2 and the Doris Duke Clinical Research Foundation.

\section{References}

Atlas, O.K., Dodds, S.D., Panjabi, M.M., 2002. Single and incremental trauma models: a biomechanical assessment of spinal instability. Eur. Spine J. 12, 205-210.

Barnsley, L., Lord, S., Bogduk, N., 1994. Whiplash injury. Pain 58, 283-307.

Barnsley, L., Lord, S.M., Wallis, B.J., Bogduk, N., 1995. The prevalence of chronic cervical zygapophysial joint pain after whiplash. Spine 20, 20-25.

Becker, E.B., 1972. Measurement of mass distribution parameters of anatomical segments. Society of Automotive Engineers Paper No. 720964.

Bogduk, N., Marsland, A., 1988. The cervical zygapophysial joints as a source of neck pain. Spine 13, 610-617.

Braakman, R., Penning, L., 1971. Injuries of the Cervical Spine. Excerpta Media, Netherlands.

Cusick, J.F., Pintar, F.A., Yoganandan, N., 2001. Whiplash syndrome: kinematic factors influencing pain patterns. Spine 26, 1252 1258.

Dvorak, J., Froehlich, D., Penning, L., Baumgartner, H., Panjabi, M.M., 1988. Functional radiographic diagnosis of the cervical spine: flexion/extension. Spine 13, 748-755.

Eichberger, A., Darok, M., Steffan, H., Leinzinger, P.E., Bostrom, O., Svensson, M.Y., 2000. Pressure measurements in the spinal canal of post-mortem human subjects during rear-end impact and correlation of results to the neck injury criterion. Accid. Anal. Prev. 32, 251-260.

Geigl, B., Steffan, H., Leinzinger, P., Roll, Muhlbauer, M., Bauer, G., 1994. The movement of head and cervical spine during rear-end impact. In: International Conference on Biomechanics of Impacts, Lyon, France, pp. 127-137.

Grauer, J.N., Panjabi, M.M., Cholewicki, J., Nibu, K., Dvorak, J., 1997. Whiplash produces an S-shaped curvature of the neck with hyperextension at lower levels. Spine 22, 2489-2494.

Ivancic, P.C., Panjabi, M., Ito, S., Cripton, P.A., Wang, J.L., 2002. A biofidelic osteoligamentous cervical spine model with muscle force replication for whiplash trauma simulation. In: Proceedings of the Cervical Spine Research Society, Miami, FL, pp. 180-182.

Jonsson Jr., H., Cesarini, K., Sahlstedt, B., Rauschning, W., 1994. Findings and outcome in whiplash-type neck distortions. Spine 19, 2733-2743.

Kaneoka, K., Ono, K., Inami, S., Yokoi, N., Hayashi, K., 1997. Human cervical spine kinematics during whiplash loading. In: International Conference on New Frontiers in Biomechanical Engineering, Tokyo, Japan.

Kaneoka, K., Ono, K., Inami, S., Hayashi, K., 1999. Motion analysis of cervical vertebrae during whiplash loading. Spine 24, 763-769.

Kumar, S., Narayan, Y., Amell, T., 2002. An electromyographic study of low-velocity rear-end impacts. Spine 27, 1044-1055.

Lord, S.M., Barnsley, L., Wallis, B.J., Bogduk, N., 1996. Chronic cervical zygapophysial joint pain after whiplash. A placebocontrolled prevalence study. Spine 21, 1737-1744. 
Luan, F., Yang, K.H., Deng, B., Begeman, P.C., Tashman, S., King, A.I., 2000. Qualitative analysis of neck kinematics during lowspeed rear-end impact. Clin. Biomech. 15, 649-657.

Magnusson, M.L., Pope, M.H., Hasselquist, L., Bolte, K.M., Ross, M., Goel, V.K., Lee, J.S., Spratt, K., Clark, C.R., Wilder, D.G., 1999. Cervical electromyographic activity during low-speed rear impact. Eur. Spine J. 8, 118-125.

Matsushita, T., Sato, T., Hirabayashi, K., Fujimura, S., Asazuma, T., 1994. X-ray study of the human neck motion due to head inertia loading. In: 38th Stapp Car Crash Conference, Warrendale, PA, pp. 55-64.

Ono, K., Kaneoka, K., Wittek, A., Kajzer, J., 1997. Cervical injury mechanism based on the analysis of human cervical vertebral motion and head-neck-torso kinematics during low speed rear impacts. Society of Automotive Engineers Paper No. 973340.

Ordway, N.R., Seymour, R.J., Donelson, R.G., Hojnowski, L.S., Edwards, W.T., 1999. Cervical flexion, extension, protrusion, and retraction. A radiographic segmental analysis. Spine 24, 240-247.

Panjabi, M.M., 1992. The stabilizing system of the spine. Part II. Neutral zone and instability hypothesis. J. Spinal Disord. 5, 390396.

Panjabi, M.M., Cholewicki, J., Nibu, K., Babat, L.B., Dvorak, J., 1998a. Simulation of whiplash trauma using whole cervical spine specimens. Spine 23, 17-24.

Panjabi, M.M., Cholewicki, J., Nibu, K., Grauer, J.N., Babat, L.B., Dvorak, J., 1998b. Mechanism of whiplash injury. Clin. Biomech. 13, 239-249.

Panjabi, M.M., Hoffman, H., Kato, Y., Cholewicki, J., 2000a. Superiority of incremental trauma approach in experimental burst fracture studies. Clin. Biomech. 15, 73-78.

Panjabi, M.M., Huang, R.C., Cholewicki, J., 2000b. Equivalence of single and incremental subfailure stretches of rabbit anterior cruciate ligament. J. Orthop. Res. 18, 841-848.

Panjabi, M.M., Miura, T., Cripton, P.A., Wang, J.L., Nain, A.S., DuBois, C., 2001. Development of a system for in vitro neck muscle force replication in whole cervical spine experiments. Spine 26, 2214-2219.

Panjabi, M.M., Nibu, K., Cholewicki, J., 1998c. Whiplash injuries and the potential for mechanical instability. Eur. Spine J. 7, 484- 492.
Penning, L., 1978. Normal movements of the cervical spine. AJR Am. J. Roentgenol. 130, 317-326.

Penning, L., 1992. Acceleration injury of the cervical spine by hypertranslation of the head. Eur. Spine J. 1, 7-12.

Pettersson, K., Hildingsson, C., Toolanen, G., Fagerlund, M., Bjornebrink, J., 1997. Disc pathology after whiplash injury. A prospective magnetic resonance imaging and clinical investigation. Spine 22, 283-287.

Richter, M., Otte, D., Pohlemann, T., Krettek, C., Blauth, M., 2000. Whiplash-type neck distortion in restrained car drivers: frequency, causes and long-term results. Eur. Spine J. 9, 109-117.

Spitzer, W.O., Skovron, M.L., Salmi, L.R., Cassidy, J.D., Duranceau, J., Suissa, S., Zeiss, E., 1995. Scientific monograph of the Quebec Task Force on Whiplash-Associated Disorders: redefining "whiplash" and its management. Spine 20, 1S-73S.

Svensson, M.Y., Bostrom, O., Davidsson, J., Hansson, H.A., Haland, Y., Lovsund, P., Suneson, A., Saljo, A., 2000. Neck injuries in car collisions - a review covering a possible injury mechanism and the development of a new rear-impact dummy. Accid. Anal. Prev. 32, $167-175$.

Svensson, M.Y., Lovsund, P., Haland, Y., Larsson, S., 1993. Rear-end collisions - a study of the influence of backrest properties on headneck motion using a new dummy neck. In: SAE International Conference and Exposition, Detroit, MI, pp. 129-142.

Szabo, T.J., Welcher, J.B., 1996. Human subject kinematics and electromyographic activity during low speed rear impacts. Society of Automotive Engineers Paper No. 962432.

Walker, L.B., Harris, E.H., Pontius, U.R., 1973. Mass, volume, center of mass, and mass moment of inertia of head and head and neck of human body. Society of Automotive Engineers Paper No. 730985 .

White III, A.A., Panjabi, M.M., 1990. Clinical Biomechanics of the Spine, Second ed. JB Lipincott, Philadelphia. p. 110.

Yoganandan, N., Pintar, F.A., Klienberger, M., 1998. Cervical spine vertebral and facet joint kinematics under whiplash. J. Biomech. Eng. 120, 305-307.

Yoganandan, N., Pintar, F.A., Maiman, D.J., Cusick, J.F., Sances Jr., A., Walsh, P.R., 1996. Human head-neck biomechanics under axial tension. Med. Eng. Phys. 18, 289-294. 